\title{
Arsitektur Enterprise Sistem Informasi Institusi Perguruan Tinggi Menggunakan Zachman Framework
}

\author{
Dwi Agustina $\mathbf{M}^{1)}$; Teguh Susyanto2); Setiyowati ${ }^{3)}$ \\ 1) 2) Program Studi Sistem Informasi, STMIK Sinar Nusantara \\ 3) Program Studi D3 Sistem Informasi, STMIK Sinar Nusantara \\ 1)agustinadwi.94@gmail.com; ${ }^{2)}$ teguh@sinus.ac.id;3) setiyowati@sinus.ac.id
}

\begin{abstract}
The higher education program in Indonesia is developing and growing very rapidly and which is followed by the increasing business needs of the organization. Increasing the data and information in business functions which is conducting by college became the use of information systems the college. The lack of planning in appropriate developing information system process will obstruct on completing university's strategies. In this study, the method of collecting data and information is observing and interviewing system users and collecting documents related to business processes. The design of enterprise architecture uses the Zachman Framework with the perspective of the planner (scope), owner (business model), and designer (system model). The researchers expect that the result can be a roadmap for the planning design which is proposed to make it easier for students and employees.
\end{abstract}

Keywords: Blueprint, Strategic Planning, Enterprise Architecture, Zachman Framework.

\section{PENDAHULUAN}

Perancangan sistem informasi secara menyeluruh untuk perguruan tinggi membutuhkan tata kelola yang baik agar kebutuhannya selaras dengan kebutuhan proses bisnis perguruan tinggi. Semakin berkembangnya teknologi informasi maka dalam merancang tata kelola teknologi informasi membutuhkan kerangka kerja atau framework. Peranan dari kerangka kerja teknologi informasi adalah untuk memastikan bahwa teknologi informasi dapat digunakan secara maksimal, resiko teknologi informasi dikelola secara tepat, dan membangun arsitektur informasi dan meningkatkan visibility dari teknologi informasi. Untuk mencapai tujuan tersebut dibutuhkan perencanaan, implementasi, dukungan, pengawasan dan evaluasi yang matang dan optimal dari pihak perguruan tinggi. Sebagai sebuah perguruan tinggi di , Politeknik XYZ telah menggunakan sistem yang berbasis web lokal akan tetapi belum secara menyeluruh dan masih banyak terdapat kendala. Cakupan jaringan pemrosesan data masih dilakukan secara parsial, tidak terintegrasi. Sistem informasi yang tidak terintegrasi ini menyebabkan proses pengisian data menjadi kurang efisien disebabkan karena sering kali terjadi pengisian data yang berulang (redundansi). Berdasarkan kondisi dan masalah tersebut, maka butuhkan suatu Perencanaan arsitektur data baru yang dapat memenuhi kebutuan proses bisnis di organisasi, serta dibutuhkan arsitektur informasi yang dapat memberikan informasi yang akurat dan pelaporan yang lengkap dengan tujuan agar dapat menjadi acuan dalam menetapkan kebutuhan sistem.

Penelitian yang sama telah dilakukan di STP Trisakti, penelitian tersebut bertujuan untuk membuat arsitektur enterprise perencanaan strategis $\mathrm{SI} / \mathrm{TI}$ perguruan tinggi dalam bentuk blueprint IT dengan Zachman Framework di STP Trisakti. Penelitian tersebut menggunakan 5 perspektif yaitu Scope, Enterprise Model, System Model, Technology Model dan Functional Areas yang dibangun dari pertanyaan umum yaitu What, How, Where, Who, When, dan Why.[1][2]

\section{TINJAUAN PUSTAKA}

Tinjauan pustaka yang berisi pustaka dan hasil penelitian yang pernah dilakukan oleh penelitian terdahulu yang mana isi pustaka berhubungan dengan penelitian ini.

\subsection{Perencanaan Strategi Sistem Informasi} Identifikasi portofolio aplikasi Sistem Informasi berbasis komputer yang akan mendukung organisasi dalam pelaksanaan rencana bisnis dan merealisasikan tujuan bisnisnya. Perencanaan strategis SI/TI mempelajari pengaruh $\mathrm{SI} / \mathrm{TI}$ terhadap kinerja bisnis dan kontribusi bagi organisasi dalam memilih langkah-langkah strategis yang dilakukan dengan: 
1. Mendefinisikan tujuan Politeknik XYZ.

2. Menetapkan sasaran Politeknik XYZ.

3. Menentukan ruang lingkup Politeknik XYZ.

4. Menetapkan metodologi yang digunakan untuk perancangan sistem informasi institusi Politeknik XYZ .

5. Menentukan partisipan-partisipan dalam proses bisnis.

6. Mekanisme manajemen agar sistem dapat terintegrasi dengan baik.

7. Perencanaan kerja perancangan sistem informasi institusi [2].

\subsection{Kerangka Kerja Zachman Framework}

Perancangan enterprise dengan

Zachman Framework ini menggunakan perspektif planner (scope), owner (enterprise model), dan designer (system model). Proses pemetaan masalah kedalam kerangka Zachman untuk menghasilkan rancangan sistem yang dibutuhkan yang selanjutnya akan disusun dalam kerangka matrik Zachman. Setelah matrik Zachman diperoleh maka masing-masing baris dan kolom pada matrik tersebut akan diuraikan satu per satu yang dibangun dari pertanyaan What, How, Where, Who, When dan How [2].

\subsection{Analisis SWOT}

Analisis SWOT didasarkan pada logika yang dapat memaksimalkan kekuatan (strengths) dan peluang (opportunities), namun secara bersamaan dapat meminimalkan kelemahan (weakness) dan ancaman (threats). Proses pengambilan keputusan strategis selalu berkaitan dengan pengembangan misi, tujuan, strategi dan kebijakan Politeknik XYZ. Analisis SWOT mengacu pada hasil wawancara dan kuisioner terhadap beberapa pihak terkait. Wawancara meliputi identifikasi lingkungan internal berupa kekuatan, kelemahan yang didapatkan dari analisis faktor pelayanan, faktor pengajar dan fasilitas pendukung dan indentifikasi lingkungan eksternal berupa peluang serta ancaman yang didapatkan dari analisis faktor ekonomi, faktor sosial, faktor politik dan hukum, faktor teknologi, faktor pemerintah, faktor demografi sesuai dengan kondisi Politeknik XYZ. Penelitian dengan analisis SWOT dilakukan untuk menentukan kekuatan (strengths) dan peluang (opportunities), meminimalkan kelemahan (weakness) dan ancaman (threats) dari Perusahaan percetakan[3].

\subsection{Value Chain (Rantai Nilai)}

Area fungsional utama untuk model pendidikan di Politeknik XYZ untuk aktivitas utamanya terdiri dari Penyelenggaraan pendidikan (Penerimaan mahasiswa baru, Kegiatan Akademik, Manajemen Aset Pengetahuan), Penelitian Masyarakat (Pemetaan Sumber Daya Penelitian, Kegiatan Penelitian, Dokumentasi dan Publikasi Hasil Penelitian), Pengabdian Masyarakat (Pemetaan Sumber Daya Pengabdian, Kegiatan Pengabdian, Dokumentasi dan Publikasi Hasil Pengabdian) dan untuk Aktivitas Pendukung terdiri dari Administrasi Akademik, Pengelolaan Keuangan, Akuntansi dan Audit, Pengelolaan dan Pengembangan SDM, Hubungan Masyarakat dan Kerjasama, Pengelolaan Sumber Daya Teknologi Informasi/Sistem Informasi, Pengelolaan dan Manajemen Aset [4].

\subsection{Penelitian Terkait}

Penelitian yang berjudul "Pengembangan Blueprint IT dengan Zachman Framework di STP TRISAKTI". Berdasarkan analisa hasil penelitian dan pembahasan yang dilakukan maka dapat di peroleh kesimpulan bahwa blueprint IT yang dihasilkan sesuai dengan kebutuhan STP Trisakti dalam perencanaan strategis 5 tahun ke depan. Terdapat tiga sentral utama pengembangan sistem yaitu SI Akademik, SI Keuangan modul Ledger dan Data warehouse dengan dua arsitektur aplikasi yang dikembangkan yaitu 2 tier (client-server) dan 3 tier (web base). Strategi pengembangan blueprint IT dibagi menjadi 5 tahapan yaitu tahun pertama menyelesaikan pengembangan aplikasi yang sudah ada sebelumnya dan perekrutan SDM IT yang dibutuhkan dalam pembuatan aplikasi yang baru beserta infrastrukturnya, sedangkan untuk tahun kedua sampai kelima melakukan pembuatan aplikasi yang diusulkan dengan fokus utama aplikasi yang ber-sifat strategis dan key operation pada tahun kedua, tahun ketiga key operation dan high potential, tahun keempat key operation, dan tahun kelima support [1].

Penelitian yang berjudul "Penerapan Enterprise Architecture Framework untuk Pemodelan Sistem Informasi". Berdasarkan analisa hasil penelitian dan pembahasan yang dilakukan maka dapat di peroleh kesimpulan penerapan sistem dilakukan agar mendapatkan keselarasan dengan kebutuhan bisnis. Sehingga penting bagi suatu organisasi dengan skala tertentu, untuk 
melakukan pengembangan atas sistem yang dimiliki bahkan akhirnya menjadi sistem yang kompleks. Dalam memodelkan EA dibutuhkan penggunaan framework. Dimana setiap framework baik itu TOGAF, FEAF, TEAF, Zachman Framework maupun framework lainnya, memiliki kelebihan dan kekurangan masing-masing. Oleh karena itu, penggunaan framework lebih baik disesuaikan dengan jenis EA seperti apa yang ingin dimodelkan [5].

Penelitian yang berjudul "Perancangan Arsitektur Enterprise untuk Perguruan Tinggi Swasta Menggunakan TOGAF ADM". Berdasarkan analisa hasil penelitian dan pembahasan yang dilakukan maka dapat di peroleh kesimpulan dengan menggunakan metodologi TOGAF-ADM sebagai tools yang digunakan dalam perancangan arsitektur enterprise sistem informasi, dari hasil pemetaan didapat empat sistem utama yang terdiri dari Sistem Penerimaan Mahasiswa Baru dengan 7 aplikasi, Sistem Informasi Akademik dengan 12 aplikasi, Sistem Informasi Pelepasan Akademik dengan 4 aplikasi, dan Sistem Informasi Alumni dengan 3 aplikasi. Perencanaan model enterprise arsitektur sistem informasi ini menghasilkan proses perbaikan kinerja layanan sistem informasi secara menyeluruh (ter-integrasi diseluruh unit organisasi), sehingga permasalahan adanya sistem informasi yang masih parsial untuk unit tertentu saja dapat diselesaikan sehingga dengan arsitektur sistem informasi yang terintegrasi ini, data dan informasi yang dibutuhkan dapat diperoleh dengan cepat, tepat dan akurat sesai dengan konsep sistem informasi yang baik [6][7].

Penelitian yang berjudul "Study of Implementing Zachman Framework for Modeling Information Systems for Manufacturing Enterprises Aggregate Planning". Berdasarkan analisa hasil penelitian dan pembahasan yang dilakukan maka dapat di peroleh kesimpulan bahwa Kerangka Kerja Zachman merupakan kerangka kerja yang komprehensif dan mudah dipahami. Namun demikian, ada beberapa kelemahan dari kerangka kerja ini untuk pemodelan sistem informasi diantaranya Zachman hanya mempertimbangkan membangun arsitektur baru untuk sistem informasi perusahaan tanpa mempertimbangkan sistem sebelumnya. Zachman tidak memiliki pertimbangan untuk Evaluasi dan Kontrol untuk setiap perspektif. Hasil dari setiap perspektif harus memberikan detail yang cukup untuk menentukan solusi di tingkat perspektif dan ini perlu beberapa parameter evaluasi atau paradigma kontrol. Zachman tidak memiliki pertimbangan untuk pengembangan sistem informasi yang berkelanjutan dan khususnya di perusahaan manufaktur [8].

Penelitian yang berjudul "Journal of Enterprise Architecture”. Berdasarkan analisa hasil penelitian dan pembahasan yang dilakukan maka dapat di peroleh kesimpulan bahwa konsep kunci dalam arsitektur perusahaan mencakup masalah, prinsip, model, pandangan, dan kerangka kerja. Oleh karena itu fokus pada peran prinsip-prinsip di bidang arsitektur perusahaan, di mana harus memposisikan arsitektur perusahaan sebagai sarana untuk mengarahkan transformasi perusahaan. Dalam praktiknya, banyak jenis arsitektur yang berbeda prinsip digunakan. Pada saat yang sama, prinsip disebut dengan nama yang berbeda, termasuk prinsip arsitektur, prinsip desain, dan kebijakan TI. Untuk sampai pada kerangka kerja konseptual untuk lebih memperjelas dan memposisikan jenis-jenis yang berbeda [9].

Berdasarkan pada uraian-uraian tentang penelitian terdahulu, maka penulis bermaksud meneliti dan membuat perancangan arsitektur enterprise sistem informasi institusi di Politeknik XYZ menggunakan pendekatan Zachman framework yang mencakup 3 baris perspektif yaitu Scope (Perspektif Planning), Business Model (Perspektif Owner), dan System Model (Perspektif Desiger) yang terdiri dari 6 kolom yakni Data (What), Function (How), Network (Where), People (Who), Time (When), dan Motovation (Why). Dari hasil penelitian tersebut akan menghasilkan blueprint, dimana blueprint tersebut akan menjabarkan kebutuhan data, aplikasi dan teknologi yang dapat diterapkan dan dijadikan pedoman untuk menentukan arah strategi kebijakan dan perencanaan pengembangan sistem informasi institusi di Politeknik XYZ [2].

\section{METODE PENELITIAN}

\subsection{Metode Pengumpulan Data}

\section{Observasi}

Pengamatan ini dilakukan dengan melihat proses dan kegiatan bisnis yang berjalan pada Politeknik XYZ. Observasi akan dilakukan di Gedung Utama Politeknik XYZ yang terletak di Jalan $\mathrm{KH}$. Samanhudi 
Nomor:31, Kelurahan Bumi, Kecamatan Laweyan, Kota.

\section{Wawancara}

Wawancara dilakukan pada Direktur Utama, para staff IT dan beberapa responden dari mahasiswa Politeknik XYZ. Dari hasil wawancara, maka akan dikumpulkan data dan informasi mengenai tugas, fungsi, permasalahan dan manfaat $\mathrm{TI}$ pada setiap unit kerja.

\section{Studi Pustaka}

Studi pustaka ini dilakukan dengan cara mempelajari dokumen penelitian, buku-buku, jurnal dan yang terkait dengan perancangan arsitektur enterprise sistem informasi institusi Politeknik XYZ.

\subsection{Metode Analisis Masalah}

Menganalisa hasil wawancara, observasi, dan studi pustaka sesuai kerangka penelitian dengan hasil akhir berupa dokumentasi arsitektur sistem yang menggambarkan kondisi sekarang dan rancangan Sistem Informasi Institusi Politeknik XYZ.

\subsection{Target Bagi SI/TI}

Target bagi $\mathrm{SI} / \mathrm{TI}$ terdiri dari identifikasi masalah dan solusi bisnis Internal yaitu menjelaskan tetang kekurangan sistem yang kemudian akan diajukan saran untuk melengkapi kekurangan sistem tersebut. selanjutnya, identifikasi peluang bisnis dari eksternal organisasi yaitu tanggapan lingkungan tetang sistem dan lembaga terkait. Sedangkan, Analisis Gap digunakan untuk membandingkan sistem informasi yang berjalan di lembaga terkait saat ini dengan perancangan/perencanaan sistem informasi lembaga terkait yang akan datang.

\subsection{Membuat Strategi SI/TI}

Strategis yang akan dihasilkan dalam penelitian ini adalah Strategi Manajemen untuk Sistem Informasi Politeknik XYZ dan Strategi Bisnis untuk Sistem Informasi Politeknik XYZ.

\subsection{Blueprint}

Kerangka kerja perencanaan strategi Sistem Informasi di Politeknik XYZ yang terintegrasi sehingga memudahkan manajemen mengelola sumberdaya untuk menghasilkan informasi yang dibutuhkan, akurat, dapat digunakan secara bersama oleh semua pihak

\section{HASIL DAN PEMBAHASAN}

\subsection{Analisis Lingkungan Bisnis Internal}

Berikut disajikan Tabel 1 berisi hasil analisis SWOT Politeknik XYZ secara internal.
Tabel 1. Hasil Analisis SWOT Politeknik XYZ secara Internal

\begin{tabular}{|c|c|}
\hline $\begin{array}{l}\text { Kekuatan } \\
\text { (Strenghts) }\end{array}$ & \\
\hline $\begin{array}{l}\text { 1.Adanya kerjasama } \\
\text { dengan beberapa } \\
\text { lembaga organisasi di } \\
\text { luar Politeknik XYZ } \\
\text { dalam pengembangan } \\
\text { kurikulum, kerjasama } \\
\text { dan penelitian. } \\
\text { 2.Politeknik XYZ } \\
\text { memiliki akreditasi } \\
\text { minimal B disetiap } \\
\text { program studinya. } \\
\text { 3.Memiliki staf IT dan } \\
\text { staf pengajar yang } \\
\text { memadai dan } \\
\text { berpengalaman serta } \\
\text { berkompetensi tinggi } \\
\text { dibidangnya. } \\
\text { 4.Komitmen pimpinan } \\
\text { Politeknik XYZ untuk } \\
\text { mengembangkan, } \\
\text { memanfaatkan, } \\
\text { menyediakan resource } \\
\text { dana una untuk } \\
\text { mendukung kegiatan } \\
\text { institusi. } \\
\text { 5.Tersedianya ruang } \\
\text { praktek/laboratorium, } \\
\text { infrastruktur jaringan } \\
\text { lokal dan spesifikasi } \\
\text { komputer yang selalu } \\
\text { ter-update mengikuti } \\
\text { kebutuhan SI/TI dan } \\
\text { sarana prasarana } \\
\text { pendukung lainnya } \\
\text { yang mencukupi. }\end{array}$ & $\begin{array}{l}\text { 1.Publikasi jurnal } \\
\text { nasional dan } \\
\text { internasional dosen } \\
\text { maupun mahasiswa } \\
\text { masih rendah. } \\
\text { 2.Staf pengajar tetap } \\
\text { masih perlu ditambah } \\
\text { terutama yang } \\
\text { memiliki kualifikasi } \\
\text { S3. } \\
\text { 3.Masih minimnya } \\
\text { dosen yang } \\
\text { mendapat beasiswa } \\
\text { dari DIKTI. } \\
\text { 4.Sebagian besar } \\
\text { unit belum memiliki } \\
\text { sistem informasi } \\
\text { tatakelola. } \\
\text { 5.Sistem manajemen } \\
\text { (SDM, keuangan, } \\
\text { aset dan fasilitas) } \\
\text { yang saat ini } \\
\text { digunakan belum } \\
\text { sepenuhnya tuntutan } \\
\text { memenuhi tuntan } \\
\text { good university } \\
\text { governance. }\end{array}$ \\
\hline
\end{tabular}

\subsection{Analisis Lingkungan Bisnis Eksternal}

Berikut disajikan Tabel 2 berisi hasil analisis SWOT Politeknik XYZ secara eksternal.

\section{Tabel 2. Hasil Analisis SWOT Politeknik XYZ} secara Eksternal

\begin{tabular}{|c|c|}
\hline $\begin{array}{r}\text { Pel } \\
\text { (Oppo }\end{array}$ & \\
\hline $\begin{array}{l}\text { 1.Terbuka lebar untuk } \\
\text { kerjasama dengan } \\
\text { pihak eksternal terkait } \\
\text { dengan infrastruktur, } \\
\text { maintenance legal } \\
\text { hardware, dan } \\
\text { software dan pelatihan } \\
\text { dosen dan } \\
\text { mahasiswa. } \\
\text { 2.Politeknik dapat } \\
\text { membuka jenjang } \\
\text { pendidikan D IV. }\end{array}$ & $\begin{array}{l}\text { dan peng } \\
\text { kepada mas } \\
\text { dalam } \\
\text { teknologi inform } \\
\text { maya hidup } \\
\text { masyarakat Ino }\end{array}$ \\
\hline
\end{tabular}




\begin{tabular}{|c|c|}
\hline $\begin{array}{c}\text { Peluang } \\
\text { (Opportunities) }\end{array}$ & \\
\hline 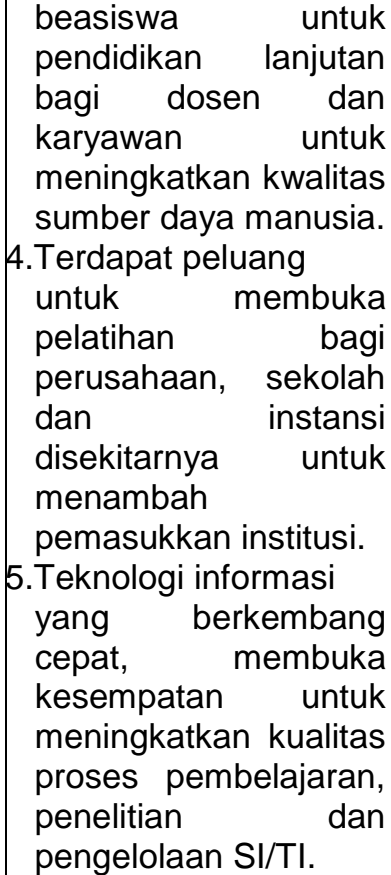 & $\begin{array}{l}\text { mengancam } \\
\text { keamanan sistem } \\
\text { informasi. } \\
\text { 4. Tingginya biaya } \\
\text { untuk } \\
\text { mengembangkan } \\
\text { sistem informasi dan } \\
\text { teknologi Informasi } \\
\text { yang baik. } \\
\text { 5.Persaingan antar } \\
\text { universitas yang } \\
\text { semakin tinggi } \\
\text { menuntut } \\
\text { pengembangan } \\
\text { kurikulum yang } \\
\text { relevan and dengan } \\
\text { kebutuhan pasar } \\
\text { global. }\end{array}$ \\
\hline
\end{tabular}

\subsection{Strategis Bisnis Sistem Informasi}

Hasil pembandingan dalam analisis SWOT yang menghasil isu - isu strategis disajikan pada Tabel 3.

\section{Tabel 3. Strategis SWOT}

\begin{tabular}{|c|c|}
\hline & \\
\hline 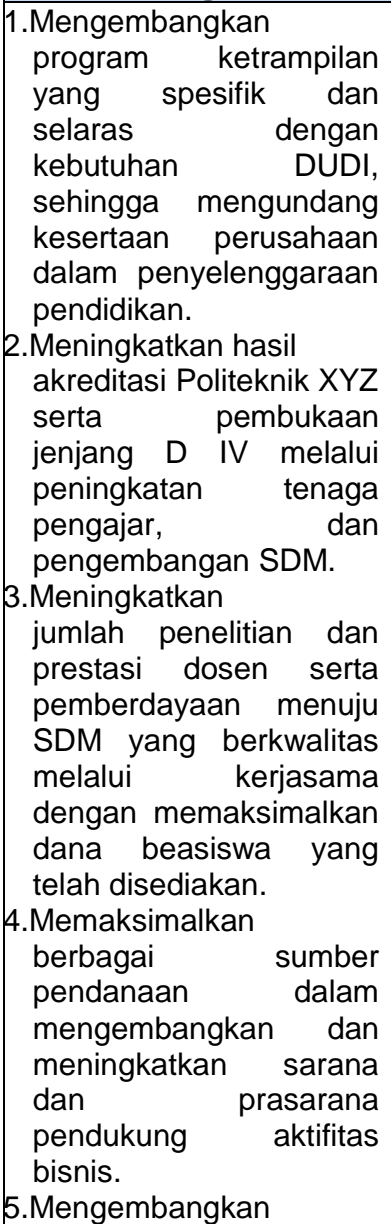 & $\begin{array}{lr}\text { beasiswa } & \text { yang } \\
\text { disediakan Politeknik } \\
\text { XYZ untuk } \\
\text { meningkatkan kwalitas } \\
\text { SDM. } \\
\text { Memaksimalkan } \\
\text { sumber dana untuk } \\
\text { mengembangkan sistem } \\
\text { informasi pada setiap } \\
\text { unit dan sistem basis } \\
\text { yang saling terintegrasi. } \\
\text { Pembangunan } \\
\text { dan peningkatan kualitas } \\
\text { sistem informasi }\end{array}$ \\
\hline
\end{tabular}

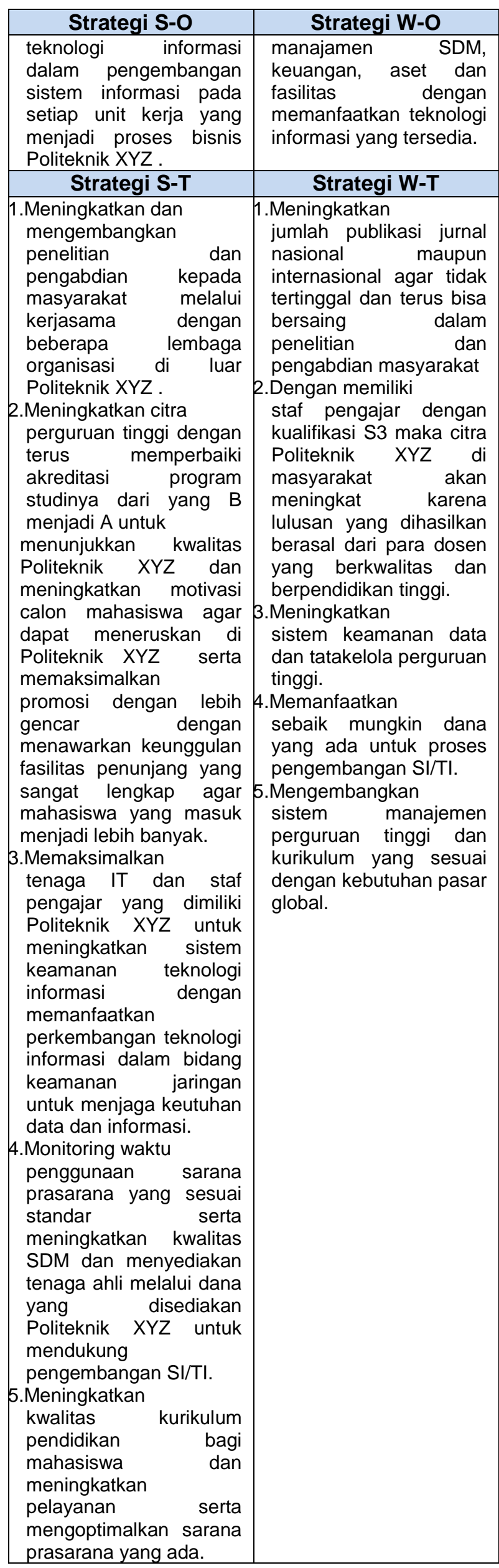




\subsection{Matrik Zachman Framework}

Berdasarkan hasil pengumpulan data maka selanjutnya akan dilakukan proses pemetaan masalah kedalam kerangka Zachman untuk menghasilkan rancangan sistem yang dibutuhkan. Matriks Zachman Framework Politeknik XYZ.

Tabel 4. Matriks Zachman Framework

\begin{tabular}{|c|c|c|c|}
\hline 滳 & 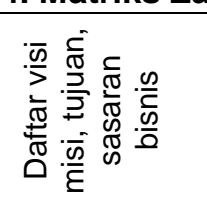 & 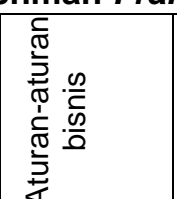 & 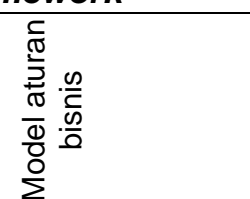 \\
\hline 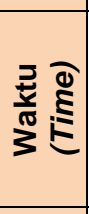 & 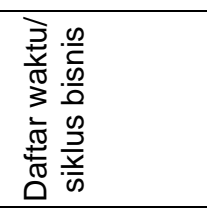 & 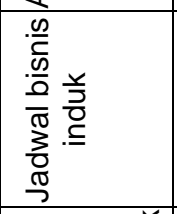 & 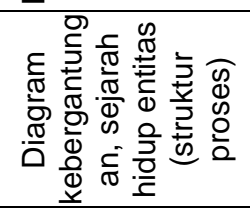 \\
\hline 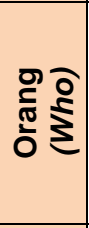 & 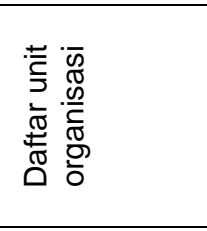 & 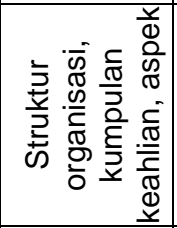 & 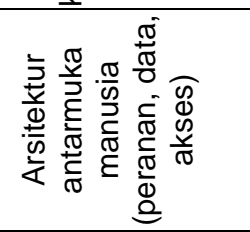 \\
\hline 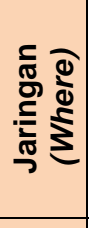 & 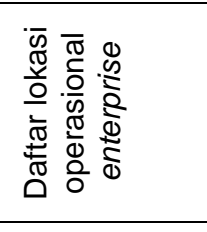 & 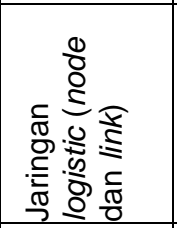 & 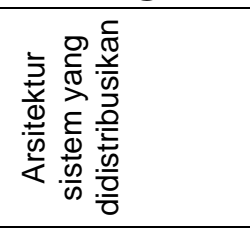 \\
\hline 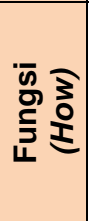 & 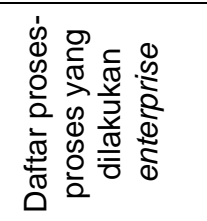 & 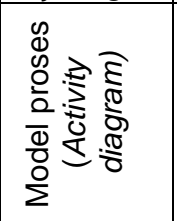 & $\begin{array}{l}\varepsilon \\
\frac{\pi}{\pi} \\
\frac{\pi}{0} \\
\frac{\pi}{0} \\
0 \\
\frac{\pi}{0} \\
\frac{\pi}{0}\end{array}$ \\
\hline 焉 & 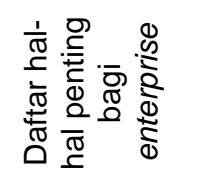 & 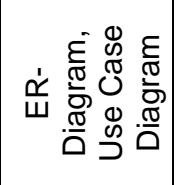 & 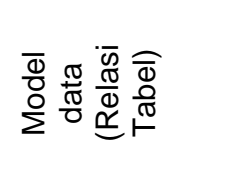 \\
\hline & 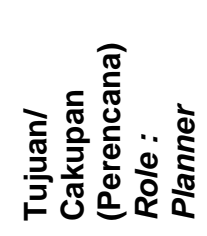 & 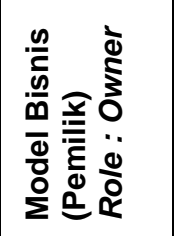 & 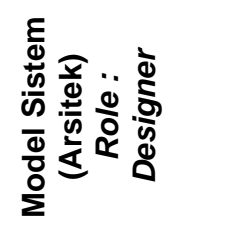 \\
\hline
\end{tabular}

\subsection{Objective/scope (contextual) Role :} Planner

\section{a. Data (What)}

Mendefinisikan kegiatan penting dalam mendukung proses bisnis.
1) Proses Bisnis Penerimaan Mahasiswa Baru
2) Proses Bisnis Penyelenggaraan Akademik
3) Proses Bisnis Pelepasan Mahasiswa
4) Proses Bisnis Alumni dan Karir
5) Proses Bisnis Perpustakaan

6) Proses Bisnis Organisasi

7) Proses Bisnis (UPPM) dan Kepakaran

b. Function (How)

Mendefinisikan semua proses bisnis yang terjadi berdasarkan fungsi bisnis yang sudah didefinisikan dan sesuai dengan sasaran pengembangan Politeknik XYZ untuk mencapai tujuan yaitu (1) Manajemen Akademik, (2) Manajemen Pembelajaran Digital, (3) Manajemen Organisasi, (4) Portal Penelitian dan Pengabdian Masyarakat, (5) Manajemen Pendukung, (6)

c. Network (Where)

Mendefinisikan lokasi bisnis yang akan digunakan untuk mengimplementasikan Sistem Informasi. Lokasi pengelolaan terjadi di Kampus Politeknik XYZ dengan rincian: (1) Bidang Akademik, (2) Pembelajaran Digital, (3) Organisasi Bisnis, (4)

d. People (Who)

Mengidentifikasi setiap unit penting dalam organisasi yang terlibat dalam proses Sistem Informasi Politeknik XYZ, yaitu: (1) Bidang Akademik, (2) Pembelajaran Digital, (3) Bidang Kemahasiswaan, (4) Bidang Organisasi Bisnis, (5)

e. Time (When)

Daftar waktu atau siklus kegiatan pendidikan dan pembelajaran yang berlangsung di Politeknik XYZ, yaitu: (1) Bidang Akademik, (2) Bidang Penelitian, (3) Bidang Penelitian dan Pengabdian Masyarakat, (4)

f. Motivasion (Why)

Mendefiniskan Visi, Misi, Tujuan dan Sasaran Politeknik XYZ.

4.6. Enterprise Model (Conceptual) Role : Owner

(1) Data (What), Mendefinisikan Use case Diagram dan ER-Diagram, (2) Function (How), menggambarkan bagaimana aktifitas dari proses bisnis yang berjalan, (3) Network (Where), mendefinisikan kondisi jaringan teknologi informasi di Politeknik XYZ, (4) People (Who), mendefinisikan struktur organisasi berdasarkan kebutuhan sistem, (5) Time (When), mendefinisikan rencana induk untuk mendukung proses bisnis digunakan sebagai acuan atau Rencana Tindakan (Action Plan).

\subsection{Roadmap}

Berdasarkan analisa prioritisasi di atas, berikut ini adalah rekomendasi roadmap SI/TI 
Politeknik XYZ yang dipetakan selama 5 tahun juga hasil yang akan di usulkan kepada pihak Politeknik XYZ. Gambar 1 menunjukkan Roadmap dari Politeknik XYZ,

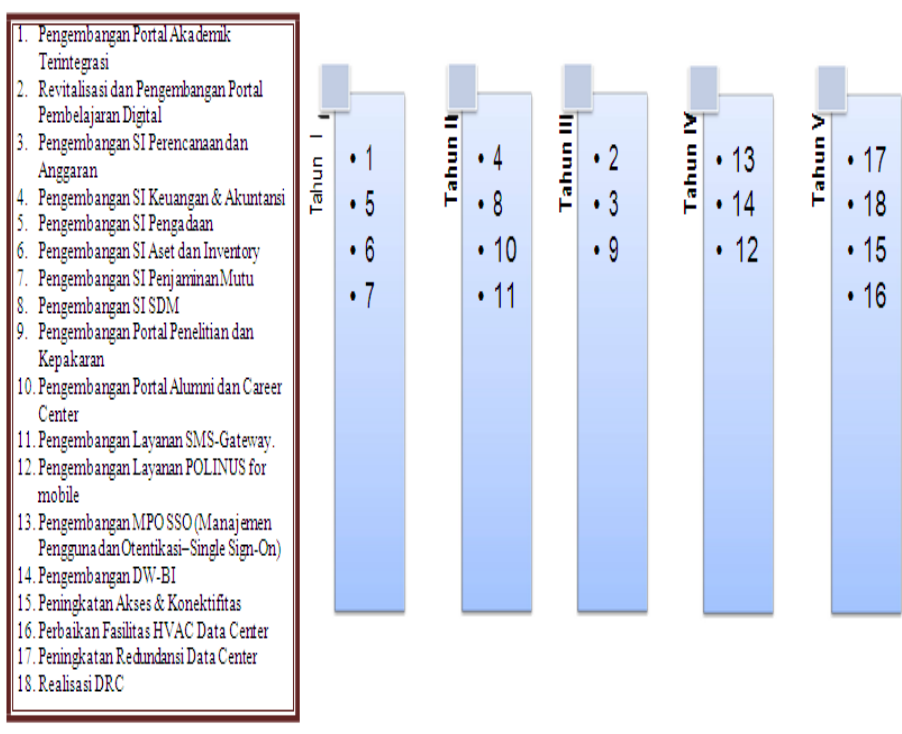

\section{Gambar 1. Roadmap}

Roadmap tersebut merupakan rencana induk pengembangan yang akan dilakukan yaitu dengan melakukan penambahan sebanyak 18 projek pada beberapa sistem di politeknik $X Y Z$ dalam waktu kurang lebih selama enam tahun dengan setiap tahun rata-rata menyelesaikan tiga sampai empat proyek.

\section{PENUTUP}

\subsection{Kesimpulan}

Hasil dari penelitian adalah sebuah blueprint arsitektur enterprise di Politeknik XYZ dengan menggunakan Zahman Framework, yang terdiri dari 18 projek yaitu (1) Portal Akademik terintegrasi, (2) Revitalisasi dan pengembangan Portal Pembelajaran Digital (3) SI Perencanaan dan Anggaran, (4) SI Keuangan \& Akuntansi, (5) SI Pengadaan, (6) SI Aset \& Inventory, (7) SI Penjaminan Mutu, (8) SI SDM, (9) Portal Penelitian \& Kepakaran, (10) Portal Alumni \& Career Center, (11) Layanan SMS Gateway, (12) Layanan Politeknik secara mobile, (13) Manajemen Pengguna Otentikasi-Single Sign On, (14) Pengembangan Data warehouse dan Business Intelegance, (15) Peningkatan Akses dan konektifitas, (16) Perbaikan Fasilitas HVAC data center, (17) Pengelolaan Redundansi Data Center, (18) Realisasi DRC. Blueprint tersebut dapat menjadi acuan bagi Politeknik XYZ dalam pengembangan sistem informasi untuk mencapai sasaran strategis institusi yang sesuai dengan tujuan institusi dan dapat dijadikan pedoman agar arah kebijakan pengembangan sistem informasi menjadi terukur dan jelas.

\subsection{Saran}

Berdasarkan hasil kajian penelitian ini, beberapa saran yang dapat diajukan adalah sebagai berikut:

1. Implementasi perencanaan arsitektur enterprise tidak akan berhasil jika faktor sukses penerapan tidak dipertimbangkan, dalam hal ini semua unsur yang terlibat dalam perencanaan dan implementasi, terutama pada level manajemen harus peduli dan menyadari pentingnya sebuah alur dalam implementasi sistem informasi enterprise.

2. Penerapan konsep zachman yang penulis lakukan baru sampai pada 3 baris perspektif yakni Scope, Enterprise Model, dan System Model oleh karena itu perlu untuk dikembangkan lebih lanjut sampai terpenuhi 36 sel matrik zachman.

\section{DAFTAR PUSTAKA}

[1] I. Technology, "Pengembangan Blueprint IT dengan Zachman Framework di STP Trisakti," pp. 1-17.

[2] J. A. Zachman, "A framework for information systems architecture," IBM Syst. J., vol. 26, no. 3, pp. 276-292, 2010, doi: 10.1147/sj.263.0276.

[3] N. D. Retnowati, "Analisis CSF, SWOT dan TOWS Studi Kasus: PT Intan Pariwara Klaten," J. Buana Inform., vol. 2, no. 1, pp. 31-37, 2011, doi: 10.24002/jbi.v2i1.306.

[4] S. Anardani and A. R. Putera, "Analisa Perancangan Enterprise Resource Planning Pada Cv. Mitra Internusa Jaya Surabaya," Multitek Indones. J. IIm., vol. 11, no. 2, p. 2017, 2017.

[5] R. Yunis and Theodora, "Penerapan Enterprise Architecture Framework Untuk Pemodelan," JSM STMIK Mikroskil, vol. 13, no. 2, pp. 159-168, 2012.

[6] R. Setiawan, "Perancangan Arsitektur Enterprise Untuk Perguruan Tinggi Swasta Menggunakan Togaf Adm," J. Algoritm., vol. 12, no. 2, pp. 548-561, 2016, doi: 10.33364/algoritma/v.122.548.

[7] C. Chiu, A. S. Kohli, and Z. Chaczko, "Manuscript Keywords Smart Hospital 
System, Open Group Architecture Framework (TOGAF), Integration Frameworks, Service Oriented Architecture (SOA)," Int. J. Adv. Comput. Sci., vol. 2, no. 2, pp. 56-64, 2012.

[8] D. Pelawi, C. Willy, and B. Irwanza, "Teknologi Informasi Pada Pt. Tripuri Mitra Nobelindo," ComTech, vol. 2, pp. 341-355, 2011. 